\title{
Article
}

\section{Where is the risk of bias? Considering intervention reporting quality}

\author{
Gordon, Morris
}

Available at http://clok.uclan.ac.uk/16873/

Gordon, Morris ORCID: 0000-0002-1216-5158 (2017) Where is the risk of bias? Considering intervention reporting quality. Medical Education. ISSN 03080110

It is advisable to refer to the publisher's version if you intend to cite from the work. http://dx.doi.org/10.1111/medu.13277

For more information about UCLan's research in this area go to http://www.uclan.ac.uk/researchgroups/ and search for <name of research Group>.

For information about Research generally at UCLan please go to http://www.uclan.ac.uk/research/

All outputs in CLoK are protected by Intellectual Property Rights law, including Copyright law. Copyright, IPR and Moral Rights for the works on this site are retained by the individual authors and/or other copyright owners. Terms and conditions for use of this material are defined in the policies page.

\section{CLoK}

Central Lancashire online Knowledge www.clok.uclan.ac.uk

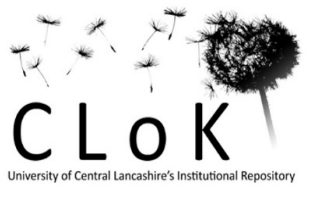




\section{Where is the risk of bias? Considering intervention reporting quality}

Morris Gordon

1. School of Medicine, University of Central Lancashire, Preston, UK

2. Families Division, Blackpool Victoria Hospital, Blackpool, UK

\begin{tabular}{|c|c|}
\hline Corresponding Author: & Dr Morris Gordon \\
\hline & Harrington Building HA118, \\
\hline & School of Medicine, \\
\hline & University of Central Lancashire, \\
\hline & Fylde Road, \\
\hline & Preston, \\
\hline & Lancashire PR1 2HE, \\
\hline & UK \\
\hline & Email: morris@betterprescribing.com \\
\hline
\end{tabular}

Word Count (excluding references): 392

Keywords: Systematic review, evidence based medical education, evidence synthesis, risk of bias, quality assessment

Declaration of Interests: None to declare

Funding: None Ethical Approval: none sought 
I read with great interest the systematic review by Horsely et al. ${ }^{1}$ This study deploys a robust and transparent methodology to highlight the scale of reporting weaknesses within health education research. As a scholar who works as an Editor for both Cochrane and the Best Evidence Medical Education Collaborative (BEME), ${ }^{2}$ these findings do not surprise me. When considering clinical and educational research as part of systematic reviews, such weaknesses are frustratingly homogenous. The author's proposal to mirror shifts within Cochrane to judge quality of health education trials in other ways than simple checklists is one I wholeheartedly support. This is already reflected in risk of bias systems proposed as part of current protocols for systematic review within BEME. ${ }^{3}$ However, I would maintain that if the focus is shifted from secondary review to primary researchers, the use of CONSORT ${ }^{4}$ guidance to support writing of manuscripts would cover most items considered within such risk of bias tools and significantly enhance reporting.

An area that such novel risk of bias tools would fail to consider is related to reporting of educational interventions themselves. Within the context of pharmacological trials, there is a clearly understood interventional agent. As such, replication and dissemination of findings is not impacted by understanding the agent itself, rather how it was used and its effectiveness. Primary educational interventions are often novel, produced or adapted specifically for the study being reported and commonly poorly reported. This is a key area where study reports may vary in quality. Considering specific learning outcomes, underpinning theoretical frameworks and pedagogy are key to ensure interventions can be judged on their educational quality. This is a completely different issue to trial methodological quality, with no reason the two elements have to be in any way correlated.

Poor reporting of non-pharmacological interventions is just as commonly seen in clinical medicine trials, with calls to adapt and extend the CONSORT statement ${ }^{5}$. In following the author's suggestion to adopt Cochrane style risk of bias systems to judge quality, I would therefore propose that similar work is needed to extend such systems in the education context. They must consider the substantial variations that can exist in reporting of primary intervention as a potential source of bias and agree how to judge this. Only then can a risk of bias tool consider the quality of health education trials in a holistic and field specific manner. 


\section{References}

1. Horsley T, Galipeau J, Petkovic J, Zeiter J, Hamstra SJ, Cook D. Reporting quality and risk of bias in randomised trials in health professions education. Med Educ 2017;51:61-71

2. BEME. Best Evidence Medical Education Collaborative Homepage. BEME, 2017. http://www.bemecollaboration.org/ [Accessed on 3rd January 2017]

3. Hothersall et al. Assessing the behavioural and social science curricula components for undergraduate medical students: A BEME Systematic Review Protocol. 2016. http://bemecollaboration.org/downloads/2472/Protocol\%20Jan\%20(2016).pdf [Acessed on 3rd January 2017].

4. Begg C, Cho M, Eastwood S et al. Improving the quality of reporting of randomised controlled trials. The CONSORT statement. JAMA 1996;276 (8):637-9.

5. Hoffmann TC, Erueti C, Glasziou P. Poor description of non-pharmacological interventions: analysis of consecutive sample of randomised trials BMJ 2013; 347 :f3755 